\title{
Implementasi Image Stitching pada Aplikasi Virtual Tour Bandar Udara Internasional Supadio
}

\author{
Rizki Oktaviano $^{\# 1}$, Eva Faja Ripanti ${ }^{\# 2}$, Helen Sasty Pratiwi ${ }^{\# 3}$ \\ "Program Studi Informatika, Fakultas Teknik, Universitas Tanjungpura \\ Jl. Prof. Dr. H. Nawawi, Pontianak, Kalimantan Barat 78115 \\ ${ }^{1}$ oktavianorizki@student.untan.ac.id \\ evaripanti@untan.ac.id \\ ${ }^{2}$ helensastypratiwi@informatika.untan.ac.id
}

\begin{abstract}
Abstrak
Keberadaan suatu Bandar Udara selain sebagai pintu gerbang masuk ke suatu daerah atau negara juga merupakan simbol prestise suatu daerah atau negara yang akan di kenal atau dikenang oleh penumpang pesawat udara baik domestik maupun internasional yang datang dan pergi menggunakan pesawat udara. Fungsi bandara saat ini tidak hanya sebagai fasilitas transportasi atau hanya sebagai tempat transit untuk berpergian namun juga dapat berfungsi sebagai menjadi sebuah objek wisata yang menarik bagi banyak pengunjung, dan menjadi media promosi objek wisata yang dapat meningkatkan pertumbuhan ekonomi. Virtual tour dapat menjadi alternatif untuk mempermudah pengunjung mengakses lokasi-lokasi tertentu di kawasan bandar udara. Gambar panorama merupakan sebuah gambar dengan resolusi dan sudut pandang yang lebih luas dari gambar biasa. Gambar panorama dapat dilakukan metode image stitching. Image Stitching dilakukan dengan tiga tahapan, pertama menginputkan beberapa gambar, kemudian mengkalibrasikan gambar untuk mencari kesamaan dalam gambar, Oleh karena itu diperlukan analisis pada image stitching pada virtual tour Bandar Internasional Supadio. Aplikasi virtual tour yang dibuat akan diuji menggunakan Black-box dan UAT (User Acceptance Test). Hasil pengujian dengan metode blackbox menunjukkan sistem informasi berjalan dengan baik. Hasil yang didapat dari pengujian aplikasi menggunakan skala pengukuran Likert mendapatkan skor 2028 dengan nilai cukup positif yang berarti aplikasi dinilai berhasil dan berfungsi sebagaimana mestinya.
\end{abstract}

Kata kunci: Image Stitching, Virtual Tour, Bandar Udara, Panorama

\section{Image Stitching Implementation in Virtual Tour Application at Supadio International Airport}

\begin{abstract}
The existence of an airport apart from being a gateway to an area or country is also a symbol of the prestige of a region or country which will be known or remembered by domestic and international aircraft passengers who come and go by airplane. The current function of the airport is not only as a transportation facility or only as a transit point for traveling but can also serve as an attractive destination for many visitors, and can increase economic growth. Virtual tours can be an alternative to make it easier for visitors to access certain locations in the airport area. Virtual tour is a simulation of a real environment built online which consists of collections of panoramic images, collections of images, videos and virtual models of the actual location. A panoramic image is an image with a resolution and viewing angle wider than an ordinary image. Image panoramas can be done using image stitching method. Image stitching is carried out in three stages, first inputting several images, then calibrating the image to look for in the image. Therefore, an analysis of image stitching is required on the virtual tour of the Supadio International Airport. The virtual tour application that is made will be tested using a Blackbox and UAT (User Acceptance Test). The test results with the blackbox method show the information system is running well. The results obtained from testing the Likert measurement scale application get a score of 2028 with a positive enough value, which means the application is successful and functions well.
\end{abstract}

Keywords: Image Stitching, Virtual Tour, Airport, Panorama

\section{Pendahuluan}

Keberadaan suatu Bandar Udara selain sebagai pintu gerbang masuk ke suatu daerah atau negara juga merupakan simbol prestise suatu daerah atau negara yang akan di kenal atau dikenang oleh penumpang pesawat udara baik domestik maupun internasional yang datang dan pergi menggunakan pesawat udara. Demikiannya dengan Bandar Udara Internasional Supadio sebagai pintu gerbang wisatawan asing yang mempunyai nilai strategis 
dan prestise terhadap pengembangan perekonomian wilayah.

Menurut PT Angkasa Pura II (Persero)., Bandar Udara Internasional Supadio terletak di Kabupaten Kubu Raya, Kalimantan Barat. Bandara ini dikelola oleh PT. Angkasa Pura II. Luas Bandar Udara Supadio adalah 528 ha. Bandar udara ini awalnya dibangun pada awal tahun 1940-an sebagai Bandar Udara Sungai Durian. Pada tahun 1980-an, bandar udara ini dinamai kembali sebagai Bandar Udara Supadio. Sejak 1989, rute internasional dibuka dari Bandar Udara Supadio ke Bandar Udara Internasional Kuching. Sebagai bandar udara internasional tentunya selain melayani penerbangan domestik juga melayani penerbangan internasional artinya sebagai entryport bagi penumpang pesawat udara yang datang maupun berangkat ke luar negeri.[1]

Fungsi bandara saat ini tidak hanya sebagai fasilitas transportasi atau hanya sebagai tempat transit untuk berpergian namun juga dapat berfungsi sebagai menjadi sebuah destinasi yang menarik bagi banyak pengunjung, dan dapat meningkatkan pertumbuhan ekonomi. Hal ini juga akan berdampak pada peningkatkan fasilitas-fasilitas yang ada di bandar udara seperti pusat perbelanjaan, pusat makanan, pusat hiburan dan taman-taman. Untuk itu diperlukan informasi yang komprehensif yang tidak hanya menampilkan informasi berupa teks seperti yang telah disediakan oleh laman bandar udara, namun juga perlu

didukung oleh informasi yang lebih kaya seperti gambar yang menampilkan keseluruhan spot yang ingin dilihat oleh pengunjung, untuk dapat menampilkan itu semua di perlukan alat bantu berbasis teknologi.

Virtual Tour dapat menjadi alternatif untuk mempermudah pengunjung mengakses lokasi-lokasi tertentu di kawasan bandar udara. Virtual Tour dapat mempermudah kebutuhan para pengunjung untuk melihat gambaran secara $360^{\circ}$ sehingga semua sisi dapat terlihat secara jelas. Penggunaaan aplikasi Virtual Tour dapat menjelaskan semua kebutuhan visual seorang pengunjung tanpa harus datang ke sebuah spot yang diinginkan.

Virtual Tour adalah sebuah simulasi dari lingkungan nyata yang ditampilkan secara online yang terdiri dari kumpulan-kumpulan Gambar Panorama, kumpulan gambar, video dan virtual model dari lokasi yang sebenarnya. Istilah Virtual Tour sering digunakan untuk menggambarkan berbagai macam video dan media berbasis fotografi. Kata "panorama" mengindikasikan sebuah pandangan yang tidak terputus. Panorama berupa sekumpulan foto memanjang ataupun hasil pengambilan video yang kameranya dapat berputar/bergeser. [2]

Gambar Panorama adalah penggabungan beberapa foto yang tumpang tindih sebagian dengan tujuan untuk mendapatkan foto yang lebar dan mencakupi pemandangan yang luar. Gambar Panorama mampu merepresentasikan objek yang luas bahkan hingga $360^{\circ}$ [3] Gambar Panorama dapat dibuat dengan menggunakan metode Image Stitching. Image Stitching atau penjahitan gambar adalah proses menggabungkan gambar dengan bidang gambar yang saling tumpang tindih, yaitu pada bagian gambar pertama yang memiliki kesamaan dengan bagian gambar kedua untuk menghasilkan gambar yang beresolusi tinggi, umumnya menggunakan perangkat lunak, sebagian besar pendekatan untuk Image Stitching memerlukan kecocokan yang paling dekat diantara gambar dan tumpang tindih untuk menghasilkan gambar yang halus.

Image Stitching dilakukan dengan tiga tahapan, pertama menginputkan beberapa gambar, kemudian mengkalibrasikan gambar untuk mencari kesamaan dalam gambar, dan terakhir menggabungkan semua gambar input. Beberapa kamera digital dapat menggabungkan gambar langsung dari kamera tersebut, tetapi tidak semua bisa mendapatkan hasil yang beresolusi tinggi, tergantung dari kemampuan masing-masing kamera. Dengan penggunaan metode Image Stitching yang mampu menghasilkan gambar panorama yang beresolusi tinggi dapat di implementasikan ke sebuah Virtual Tour. Selanjutnya penggunaan Image Stitching pada aplikasi Virtual Tour ini, akan meningkatkan kualitas informasi gambar.

Virtual Tour merupakan salah satu cara yang dapat dilakukan agar pengguna mendapat informasi keseluruhan lokasi yang ada di bandar udara, seperti alur keberangkatan, check in, toilet, mushola dll. Virtual Tour dapat mempermudah untuk menjelajah lokasi secara $360^{\circ}$ sehingga pengguna lebih dapat melihat informasi dengan jelas. Perancangan Virtual Tour tersebut menggunakan metode Image Stitching agar mendapatkan kualitas gambar yang lebih baik.

\section{METODOLOGI PENELITIAN}

Metodologi penelitian yang dilakukan ini bertujuan untuk menggambarkan aktivitas penelitian yang dilakukan.

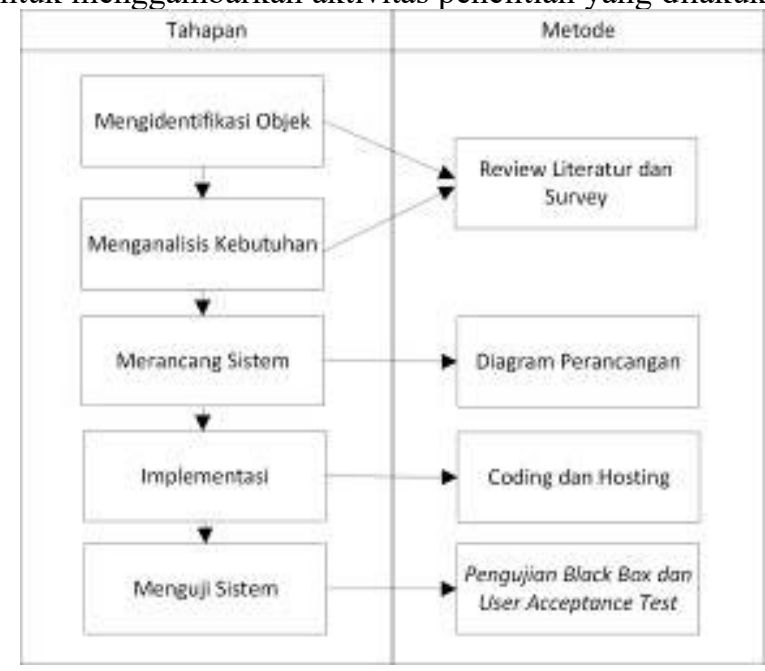

Gambar 1 Metodologi Penelitian

Pada gambar tersebut, penelitian ini dilakukan dalam tiga proses yaitu, tahapan, metode, dan hasil. Terdapat 5 tahapan di dalam proses perancangan disertai dengan metode yang digunakan, sehingga menjadi suatu hasil yang diinginkan

\section{$A$. Identifikasi Objek}

Objek pada penelitian ini seperti yang telah dijelaskan adalah bandar udara, khususnya bandar udara supadio yang merupakan salah satu fasilitas umum yang saat ini sering digunakan. Objek objek tersebut perlu di himpun 
sedemikian rupa hingga menjadi informasi yang berguna bagi pengunjung bandar udara.

Berdasarkan survey awal yang dilakukan bahwa dapat dijelaskan bahwa terdapat tiga bagian utama yang ada pada bandar udara, yaitu Public Area, Non Public Area, dan Restricted Public Area. Bagian bagian tersebut tentunya memilikin detail image seperti gambaran luas, aktivitas dan lainnya. Survey awal tersebut dilakukan dengan mendatangi bandar udara supadio pada 11 November 2019 dimana dilakukan aktivitas pengamatan dan pengambilan gambar.

Selanjutnya informasi yang didapatkan berdasarkan kegiatan survey senada dengan beberapa literatur seperti Suwarno (2001) yang telah menjelaskan tentang bagian penting bandara dan fungsi bandara dapat dibagi menjadi tiga bagian utama yaitu Public Area, Non Public Area dan Restricted Public Area, sedangkan berdasarkan keputusan Menteri Perhubunungan No. KM 48 Tahun 2002 mengenai Penyerahan Penyelenggaraan Bandar Udara Umum, disebutkan didalam suatu bandar udara terbagi menjadi dua kategori, yaitu bagian sisi udara (air side) dan sisi darat (land side). Dari sisi udara terdapat fasilitas landasan pacu, taxiway, apron, runway strip dan fasilitas pertolongan kecelakaan penerbandan dan pemadam kebakaran. Adapun dari sisi darat terdapat fasilitas terminal penumpang, terminal kargo, ATC, bangunan administrasi perkantoran, tempat parkir, marka dan rambu.

\section{B. Analisis Kebutuhan}

Berdasarkan aktivitas yang telah dilakukan sebelumnya maka didapatkan beberapa informasi terkait kebutuhan sistem dalam hal ini dibangun dalam bentuk Virtual Tour bandar udara. Terdapat 75 gambar panorama yang akan di ambil dari titik titik area yang dapat mewakili keseluruhan isi bandar udara. Gambar panorama yang sudah diambil akan disusun berdasarkan alur masuk seorang pengguna bandar udara.

Pengguna bandar udara terbagi menjadi beberapa kategori yaitu, pengguna yang ingin berangkat menggunakan pesawat terbang, pengguna yang hanya mengantar atau menjemput, pengguna yang datang untuk bekerja dan pengguna yang hanya datang untuk berwisata atau ingin membeli sesuatu yang ada pada bandar udara. Setelah gambar panorama disusun berdasarkan alur pengguna bandar udara, kemudian dibuat suatu sistem yang dapat menampilkan.

Seperti yang telah dijelaskan sebelumnya bahwa penelitian bertujuan untuk mengimplementasikan Image Stitching pada sebuah aplikasi Virtual Tour. Bandar Udara yang menjadi objek penelitian ini kemudian di identifikasi kebutuhan dan layanan minimal pengunjung. Berbagai pendekatan dilakukan untuk mengumpulkan informasi terkait kebutuhan tersebut. Studi literatur dan survey langsung diperlukan dalam proses memenuhi informasi kebutuhan minimal pengunjung sebuah bandara. Pengambilan gambar dilakukan berdasarkan area area yang diperlukan pada proses tour bandara yang dilakukan secara virtual.

Pengambilan gambar dengan Teknik panorama dilakukan pada tiap lokasi bandar udara. Hal tersebut sesuai dengan pendapat Dio (2018) dimana disampaikan bahwa teknik dan alat pengambilan gambar adalah dua hal penting dalam konsep Virtual Tour. Secara rinci juga dijelaskan bahwa secara teknis pengambilan gambar untuk kebutuhan membangun sebuah model Virtual Tour dilakukan dengan pengambilan gambar di semua sisi. Gambar yang di ambil adalah 4 gambar horizontal, 2 gambar vertikal. Pengambilan foto horizontal dilakukan dari sisi depan $\left(0^{\circ} / 360^{\circ}\right)$, kanan $\left(90^{\circ}\right)$, belakang $\left(180^{\circ}\right)$, dan kiri $\left(270^{\circ}\right)$. Sedangkan foto vertikal dilakukan dari sisi atas $\left(0^{\circ}\right)$ dan bawah $\left(180^{\circ}\right)$. Setelah melakukan pengambilan gambar, selanjutnya menentukan titik koordinat pada setiap titik gambar di ambil untuk dapat menandai gambar panorama pada map aplikasi virtual tour bandar udara internasional supadio, dengan menggunakan aplikasi google maps terdapat titik koordinat saat dilakukannya pengambilan gambar.

Langkah selanjutnya proses menggabungkan objek gambar dimana menggunakan metode Image Stitching, yang bertujuan bertujuan untuk menggabungkan gambargambar menjadi satu gambar panorama dengan menjahit bagian dari tiap-tiap gambar. Pembuatan panorama dilakukan dalam beberapa tahap seperti menentukan titik kontrol atau matching points, penggabungan gambar menjadi panorama $360^{\circ} \times 180^{\circ}$, Pada setiap gambar akan diberi kode sebagai identitas pada gambar pada saat pembuatan Virtual Tour kode tersebut akan saling berhubungan, lalu menggabungkan gambar panorama tersebut menjadi Virtual Tour, serta proses pengkodean pada aplikasi virtual tour.

Bandar Udara Internasional Supadio (Inggris: Supadio International Airport) (IATA: PNK, ICAO: WIOO), sebelumnya bernama Bandar Udara Sei Durian atau Bandar Udara Sungai Durian, adalah sebuah bandar udara internasional yang terletak di Kabupaten Kubu Raya, Kalimantan Barat, Indonesia. Jaraknya dari Kota Pontianak adalah $17 \mathrm{~km}$ sebelah selatan. Bandara ini dikelola oleh PT. Angkasa Pura II. Luas Bandar Udara Internasional Supadio adalah 528 ha. Bandar udara ini awalnya dibangun pada awal tahun 1940-an sebagai Bandar Udara Sungai Durian. Pada tahun 1980-an, bandar udara ini dinamai kembali sebagai Bandar Udara Supadio. Sejak 1989, rute internasional dibuka dari Bandar Udara Supadio ke Bandar Udara Internasional Kuching.

Bandar Udara Internasional Supadio sudah memiliki bangunan terminal baru dengan luas $32.000 \mathrm{~m}^{2}$ berkapasitas 4 juta penumpang per tahun, yang mulai beroperasi sejak tahun 2017. Gedung terminal baru juga dilengkapi dengan 4 (empat) buah garbarata demi kenyamanan penumpang yang naik-turun pesawat, namun pada tahun 2019 ditambah 3 (tiga) unit garbarata, sehingga pada tahun 2020 Bandar Udara Internasional Supadio memiliki total 7 (tujuh) fasilitas garbarata. Pada tahun 2019 juga dilaksanakan pelapisan ulang (overlay) landasan pacu sepanjang 2.250 meter yang disertai dengan perpanjangan landasan pacu sepanjang 350 meter, sehingga pada tahun 2020 panjang landasan pacu menjadi 2.600 meter. Sebelumnya, pada 2010 - 2011 landasan pacu juga telah diperlebar dari 30 meter menjadi 45 meter dan juga nanti runway bandar udara Supadio akan 
diperpanjang lagi menjadi $3.000 \times 60$ Meter yang dapat menampung pesawat Airbus A330 dan Boeing 777. Pada 2016, jumlah pergerakan penumpang domestik dan internasional di Bandara Internasional Supadio tercatat sebanyak 3,18 juta penumpang atau mengalami kenaikan dibandingkan dengan tahun sebelumnya yakni 2,71 juta penumpang. Sementara itu pada tahun 2018 jumlah pergerakan penumpang domestik dan internasional mencapai 4,2 juta penumpang, dan arus kargo eksporimpor sebanyak 23,4 juta ton.

Bandar Udara Internasional Supadio seperti yang telah disampaikan yang menjadi fokus penelitian ini kemudan diidentifkasi setiap objeknya fasilitas yang tersedia di area ini antara lain loket informasi, loket check-in, terminal keberangkatan dan kedatangan, restoran, pertokoan, ATM, toilet umum, tempat ibadah dan tempat parkir. Dikarenakan pengambilan gambar di lakukan pada tanggal 18 Juli 2020 di saat wabah pandemic Covid-19 melanda daerah Pontianak Kalimantan Barat, akses yang diberikan oleh pihak bandara sangat terbatas.

Perlu dijelaskan bahwa untuk mendukung pengambilan yang berkualitas diperlukan equipment seperti kamera, lensa, dan tripod. Software pendukung juga diperlukan untuk kebutuhan pengolahan gambar dan editing.

Setelah dilakukan pengambilan gambar pada area bandar udara, selanjutnya dilakukan tahap -tahap pemrosesan editing dan stiching untuk menghasilkan gambar panorama.

\section{Editing}

Pada tahap ini, editing dilakukan dengan menggunakan software pendunkung yaitu Adobe Photosop. Berikut adalah tahapan editing menggunakan software Adobe Photosop:

a. Image Resizing

Image Resizing adalah mengubah ukuran gambar tanpa mengubah mengubah kepadatan gambar agar kualitas gambar tidak menurun saat ukuran gambar dikecilkan. Mengubah ukuran gambar dapat menggunakan beberapa cara, salah satunya menggunakan software Adobe Photosop.

b. Removing Object

Hasil dari pengambilan gambar pada bandar udara terdapat beberapa objek foto yang tidak diinginkan, dengan menggunakan beberapa tools dari software Adobe Photoshop objek foto yang tidak diperlukan dalam gambar panorama dapat dihilangkan. Tools yang digunakan pada software Adobe Photosop akan menyesuaikan dengan objek yang akan dihilangkan.

c. Brightness and Contrast

Penyelarasan kecerahan dan kontras di perlukan pada image stitching agar tingkat kecerahan dan kontras pada setiap gambar seimbang, sehingga memudahkan di dalam proses image stitching

d. Correct Exposure

Pengambilan gambar yang dilakukan pada kondisi siang hari dan cahaya matahari sangat terang, maka terdapat beberapa hasil foto yang memiliki tingkat kecerahan dan kontras yang sangat tidak seimbang, tidak cukup menggunakan penyelarasan kecerahan dan kontras, maka diperlukan proses correct exposure, dengan menyelaraskan tinkat keseimbangan shadow dan highlight pada setiap gambar.

e. Gambar panorama yang telah melewati tahap tahap editing akan mengalami penurunan kualitas pada gambar panorama. Pada tahap ini gambar akan ditajamkan menggunakan tools high pass pada software Adobe Photosop.

\section{Stitching}

Gambar area bandar udara yang telah melwati proses editing selanjutnya akan dijahit dan digabung pada proses stitching. Berikut tahapan pada proses image stitching.

\section{a. Registration}

Gambar yang telah diedit akan di impor pada software Panoweaver dan dikonfigurasi sesuai dengan kebutuhan pada hasil output panorama.

\section{b. Matching Point}

Setelah gambar di registrasi, selanjutnya menentukan matching point pada setiap gambar. Matching point dapat dilakukan dengan cara otomatis dan manual, keduanya digunakan pada kondisi gambar yang berbeda. Pada matching point otomatis, software Panoweaver akan mendeteksi matching point pada kedua gambar yang saling tumpang tindih. Proses matching point otomatis terdapat kelemahan yaitu jarak antara pasangan titik - titik yang saling tumpang tidih semakin jauh dan melebar, maka dari itu diperlukan matching point manual untuk memperbaiki proses dari matching point otomatis

\section{c. Stitching}

Stitching dilakukan setelah gambar diproses registrasi dan dientukan matching point. Proses stitching ini berjalan otomatis pada software panoweaver dengan cara menggabungkan gambar yang saling tumpang tindih pada masing masing matching point di setiap gambar yang di registrasi dan menghasilkan output berupa gambar panorama $360^{\circ} \times 180^{\circ}$.

\section{Perancangan Sistem}

Berdasarkan hasil analasis yang telah di lakukan sebelumnya, maka terdapat beberapa komponen yang harus disiapkan dalam membangun aplikasi Virtual Tour (objek, gambar panorama, pengguna). Perancangan sistem yang di bangun pada penelitian ini mengikuti struktur yang ada pada Multimedia Development Life Cycle (MDLC). Tahapan dalam perancangan ini dilakukan dengan menggunakan Unified Modeling Language (UML) yang terdiri dari use case diagramdan, class diagram. Perancangan sistem ini digambarkan dan dijelaskan melalui arsitektur sistem bagaimana sistem ini berjalan.

\section{1) Perancangan Arsitektur Sistem}


Secara umum gambaran sistem dapat dibuat rancangan awal arsitektur sistem yang dapat dilihat pada Gambar 2 berikut

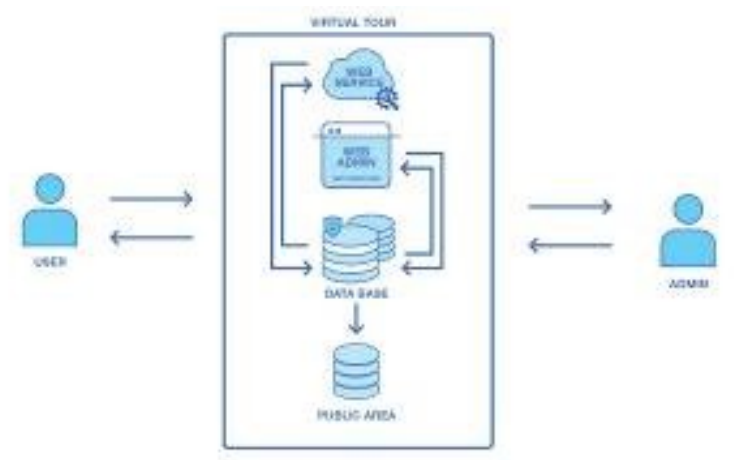

Gambar 2. Arsitektur Sistem

Aplikasi ini mengelola beberapa gambar panorama yang akan di tampilkan melalui web client service yang dapat dikunjungi oleh pengguna Bandar Udara Internasional Supadio ketika di bandar udara maupun di luar area bandar udara yang dapat membantu pengguna untuk mengoptimalkan fasilitas-fasilitas yang ada di bandar udara. Gambar panorama tersebut akan di simpan di dalam data base berdasarkan wilayah yaitu public area. Gambar yang terdapat di dalam data base dikelola oleh admin yang dapat di akses melalui web admin, admin dapat menambahkan gambar panorama, menghapus gambar panorama, mengubah titik lokasi gambar panorama, mengubah keterangan gambar panorama dan menyambungkan antar titik lokasi gambar panorama dengan gambar panorama yang lainnya untuk menambah experience dalam menggunakan aplikasi ini

\section{2) Unified Modelling System (UML)}

Unified Modelling Language (UML) ini menggambarkan pemodelan dan komunikasi mengenai sebuah sistem dengan menggunakan diagram dan teksteks pendukung. UML memiliki 13 macam diagram yang penggunaannya tidak dibakukan, semua tergantung kebutuhan dan konteksnya (Rosa, 2016).

Perancangan yang digunakan pada penelitian ini digambarkan dalam bentuk Class Diagram untuk menggambarkan suatu struktur sistem yang akan dibangun, Use Case Diagram untuk mendeskripsikan fungsi apa saja yang ada di dalam sistem dan siapa saja yang berhak menggunakan fungsi-fungsi itu

\section{a. Class Diagram}

Class Diagram menggambarkan struktur sistem dari pendefinisian kelas-kelas yang akan dibuat untuk membangun sistem. Struktur sistem harus dapat melakukan fungsi-fungsi yang sesuai dengan kebutuhan sistem dan saling berhubungan satu dengan yang lain, dapat dilihat pada Gambar 3 berikut

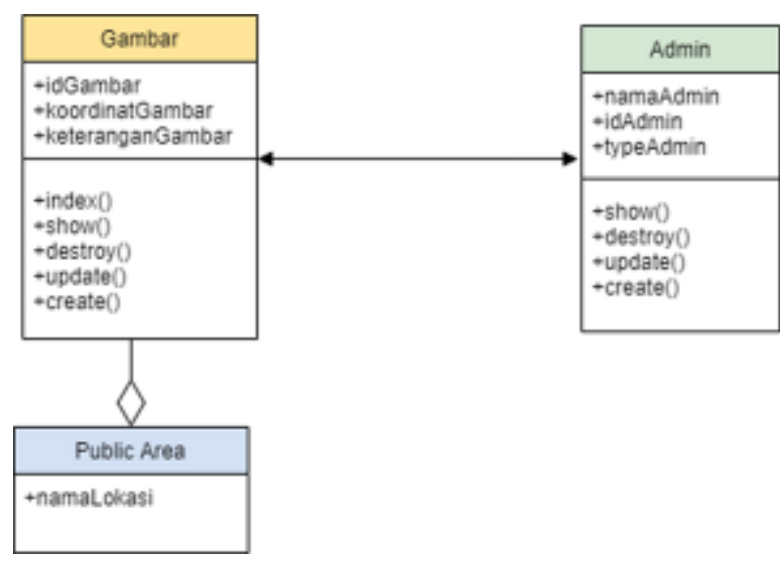

Gambar 3. Class Diagram Virtual Tour Bandar Udara

b. Use Case Diagram

Use Case Diagram merupakan pemodelan untuk perilaku aktor di dalam sistem informasi yang dibuat. Use Case Diagram menggambarkan interaksi antara satu atau lebih aktor terhadap sebuah sistem. Sistem yang dibangun berbasis komputer dan kebutuhan objek-objek yang telah didefinisikan kedalam Class Diagram akan diterjemahkan kedalam aplikasi berbasis komputer. Sehingga Use Case Diagram yang dibangun seperti pada Gambar 3.4 berikut.

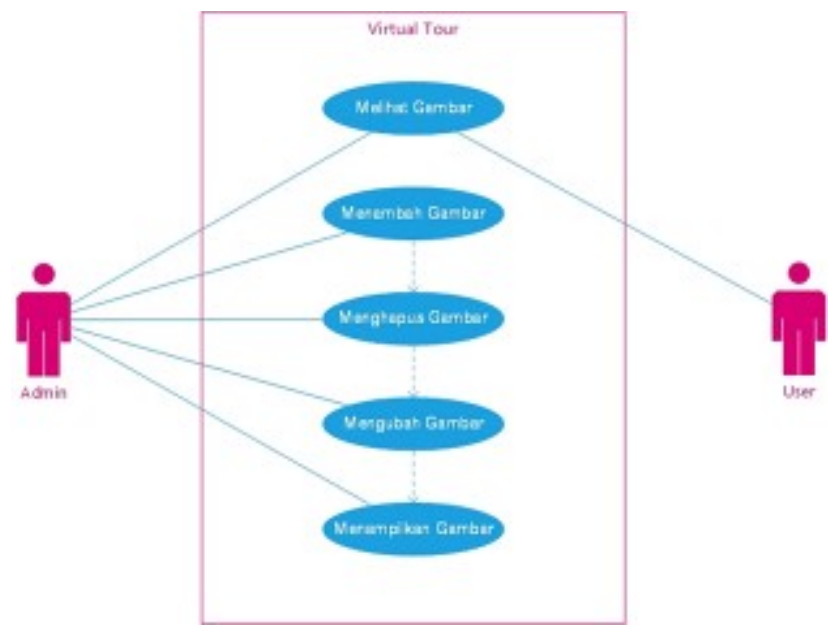

Gambar 4. Use Case Diagram Virtual Tour Bandar Udara

\section{3) Perancangan Antar Muka}

Perancangan antarmuka (interface) dirancang sebagai gambaran awal sistem yang akan dibangun. Perancangan antarmuka sistem meliputi beberapa pengguna diantaranya pengunjung bandar udara, pekerja bandar udara, penumpang bandar udara, dan admin. 


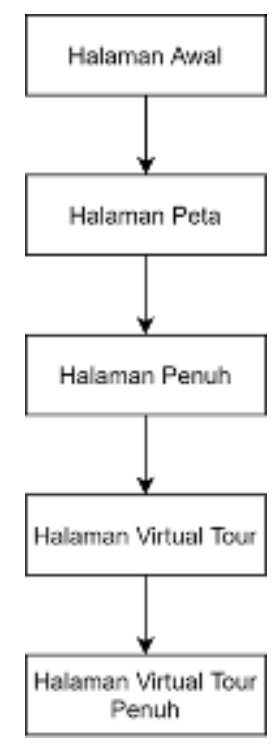

Gambar 5. Struktur Antarmuka Virtual Tour

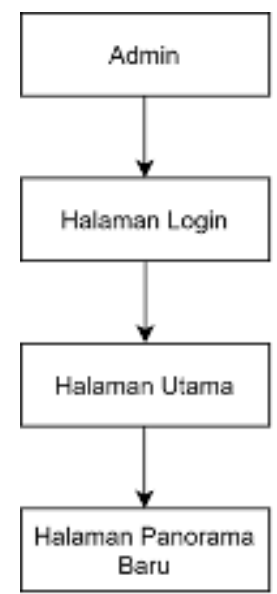

Gambar 6. Struktur Antarmuka Admin Virtual Tour

\section{HASIL DAN PEMBAHASAN}

\section{A. Hasil Penelitian}

\section{1) Proses Image Stitching}

Proses Image Stitching pada aplikasi ini menggunakan software Panoweaver. Hasil foto yang telah didapat pada pengumpulan data akan dilakukan penjahitan gambar agar menjadi satu gambar panorama untuk yang kemudian akan digunakan sebagai Aplikasi Virtual Tour Bandar Udara Internasional Supadio. Berikut adalah foto yang akan di jahit ditampilkan pada Gambar 7.

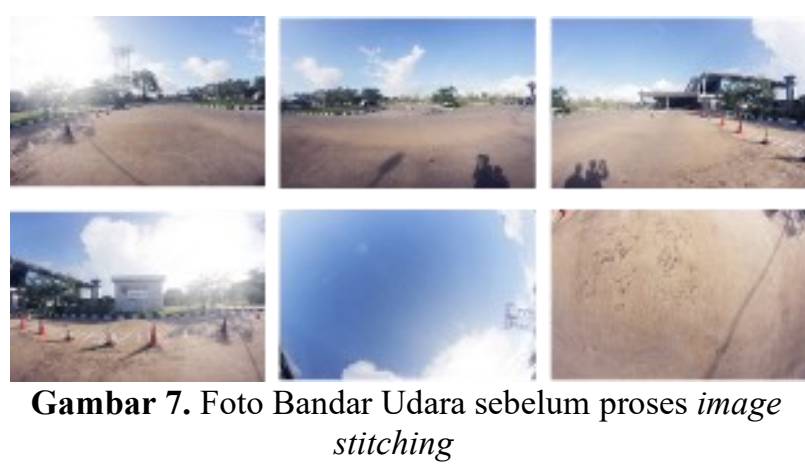

Sebelum dilakukan proses image stitching, gambar Hasil Gambar Panorama diatas telah melewati beberapa langkah - langkah editing dengan menggunakan software Adobe Photosop, diantaranya

a) Image Resizing

Mengubah ukuran skala gambar dari 5184 x 3456px ke 2000px x 1333px agar dapat dengan mudah dan cepat di jahit pada proses Image Stitching.

\section{b) Removing Objects}

Semua foto yang telah di ambil pada bandar udara terdapat terdapat objek-objek yang tidak diinginkan seperti, bayangan juru potret dan sebagian tubuh juru potret masuk di dalam foto. Menghilangkan objek dilakukan dengan cara menyeleksi objek yang tidak diinginkan pada foto dan menempelkan bagian foto lain yang terdapat di sekitar objek dengan memperhalusnya.

c) Brightness and Contrast

Pada setiap foto bandar udara yang di ambil mempunyai tingkat kecerahan dan kontras yang berbeda, dikarenakan banyak sedikitnya cahaya yang masuk terhadap lensa, oleh karena itu dilakukan langkah penyelarasan tingkat kecerahan dan kontras pada setiap gambar.

d) Correct Exposure

Terdapat beberapa foto bandar udara yang tingkat kecerahan dan kontrasnya berbeda sangat jauh dengan yang lainnya, penyelarasan untuk foto ini tidak dapat dilakukan dengan penyelarasan kecerahan dan kontras, maka dari itu dibutuhkan langkah correct exposure. Correct exposure bekerja pada bagian shadow dan highlight foto, dengan mengatur amount, tone dan radius. Serta menyesuaikan color dan midtone pada shadow dan highlight.

e) High Pass

Setelah melewati langkah - langkah penyelarasan di atas, kualitas suatu foto akan menurun, oleh karena itu dilakukan langkah yang terakhir, yaitu menajamkan foto dengan langkah high pass. Dengan menambahkan suatu lapisan diatas foto guna untuk menajamkan ujung ujung sisi dari suatu objek, lalu di blending dengan mode overlay, agar membuat perpaduan antar lapisan foto menjadi merata dengan menggelapkan warna dan membuat terang objek foto 
Berikut adalah foto bandar udara sebelum dan sesudah dilakukan tahap editing.

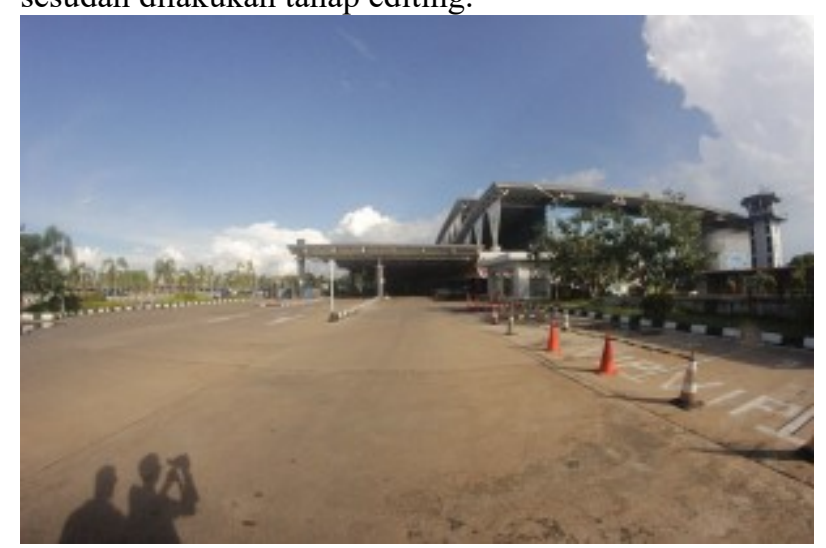

Gambar 8. Foto Bandar Udara sebelum proses editing

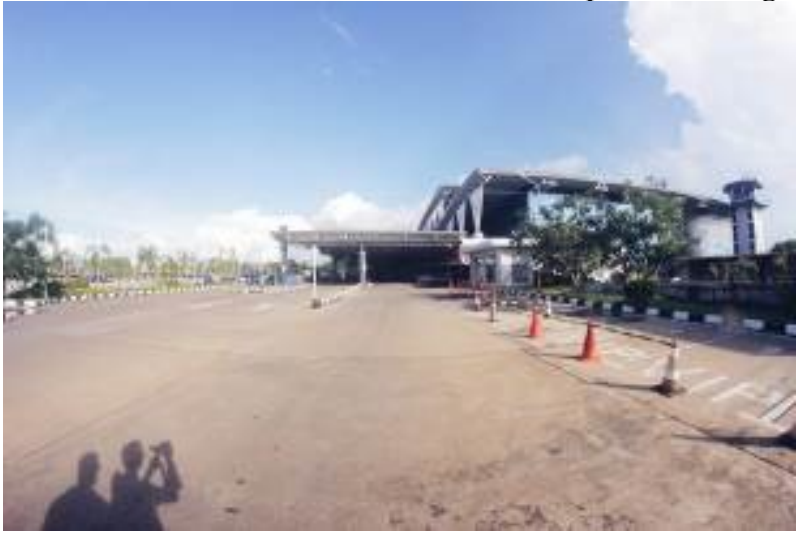

Gambar 9. Foto Bandar Udara sesudah proses editing

Setelah melauli tahap editing selanjutnya foto - foto tersebut akan dijahit menggukanan software panoweaver. Berikut adalah langkah langkah proses image stitching

\section{a) Registration}

Pada tahap ini, foto yang sudah melalui proses editing lalu diimpor ke dalam software panoweaver, dengan konfigurasi sebagai berikut:

- Image Type: Wide-angle/Normal

- Hor. Fov: 120 Deg

- Panorama Type: Spherical Panorama

- $\quad$ Output Size: 3000px x 1500px

\section{b) Matching Point}

Setelah foto tersebut di registrasi selanjutnya menentukan matching point pada masing masing foto yang saling tumpang tindih dengan minimal 3 titik yang cocok. Berikut gambar menentukan matching point

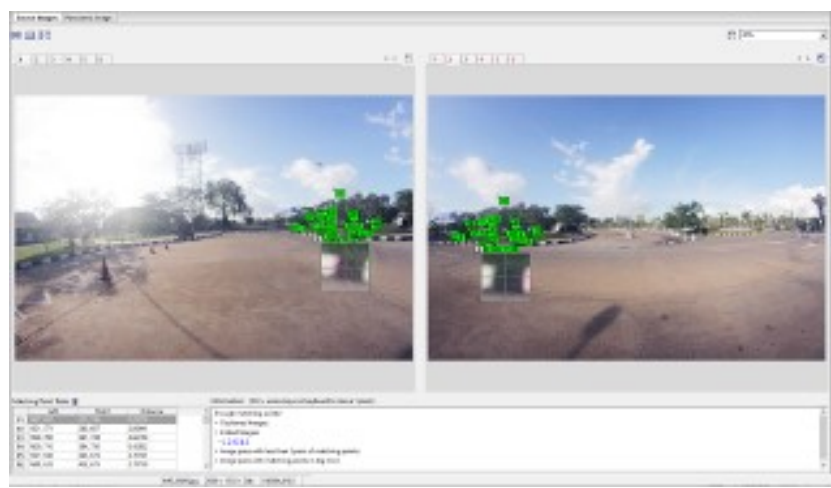

Gambar 10. Matching Point Foto 1 dan 2

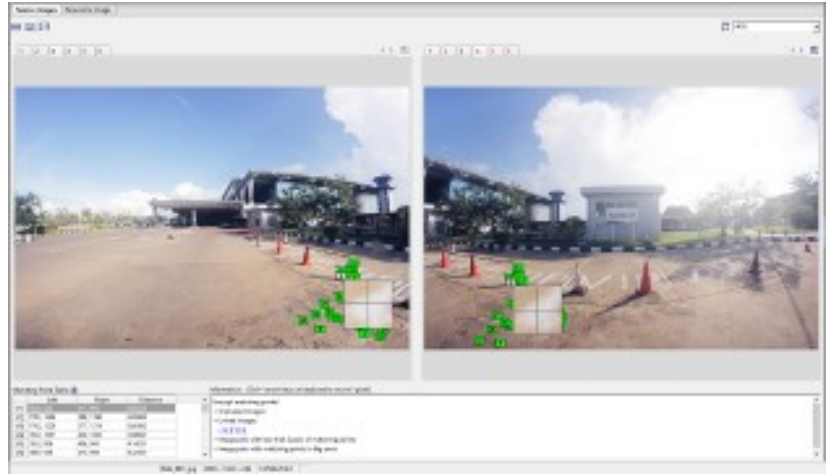

Gambar 11. Matching Point Foto 1 dan 2

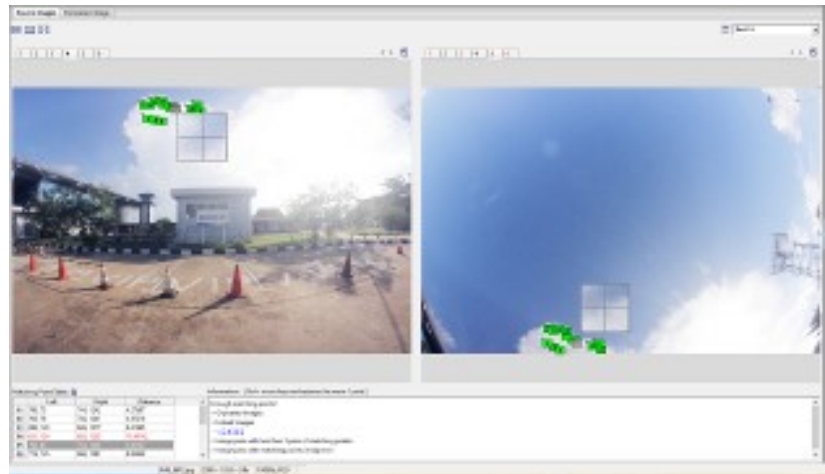

Gambar 12. Matching Point Foto 1 dan 2

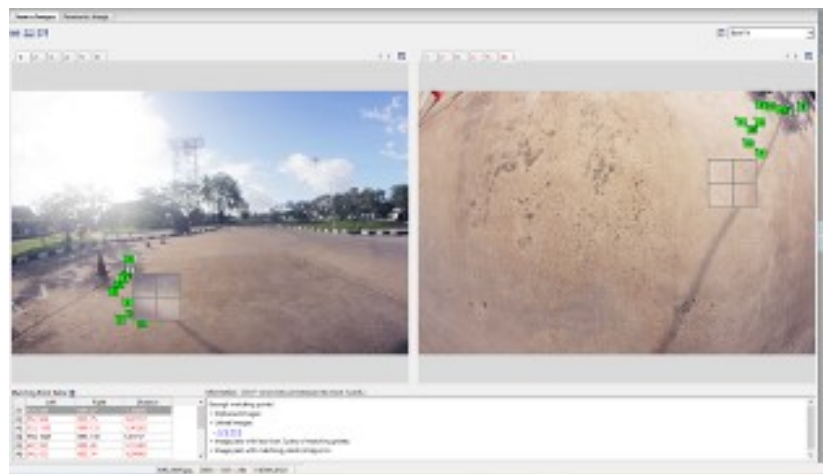

Gambar 13. Matching Point Foto 1 dan 2

\section{c) Stitching}

Selanjutnya dilakukan proses penjahitan gambar yang secara otomatis dilakukan oleh panoweaver. Berikut adalah hasil Gambar Panorama yang sudah di stitching 


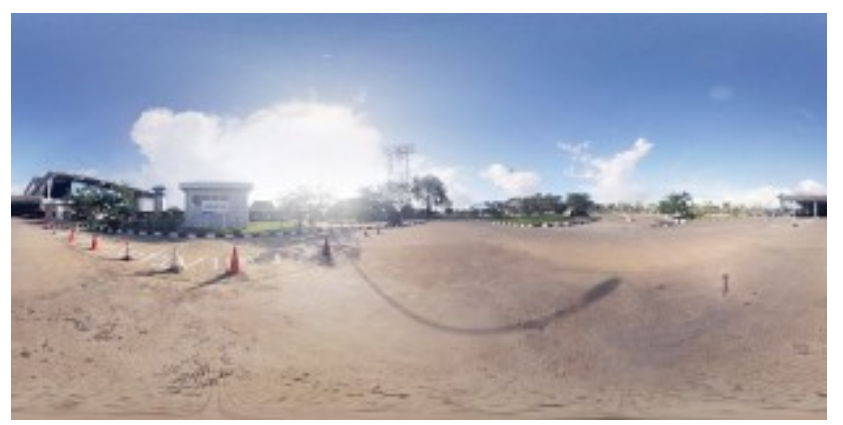

Gambar 14. Hasil Gambar Panorama setelah dilakukan proses Stitching

\section{B. Hasil Pengujian}

Pengujian aplikasi dilakukan untuk mendapatkan informasi dan mengetahui apakah aplikasi sudah dapat berjalan dengan baik dan apakan aplikasi sudah mencapai tujuan atau tidak. Pengujian pada Aplikasi Virtual Tour ini dilakukan dengan 2 jenis pengujian, yaitu pengujian Black Box untuk mengetahui hasil output sistem dan memeriksa fungsional dari sistem, serta pengujian UAT (User Acceptance Test) untuk mengetahui kelayakan sistem yang diuji secara langsung dan berinteraksi dengan sistem untuk melihat fungsi yang ada jika telah berjalan sesuai dengan kebutuhan.

\section{1) Pengujian Black Box}

Metode pengujian Black Box dipilih karena metode pengujian tersebut tidak memperhatikan struktur logika internal (coding) dalam perangkat lunak. Pengujian Black $B o x$ ini berfokus pada persyaratan fungsional sistem yang telah dibuat. Pengujian ini perlu dilakukan untuk melihat respon yang diberikan oleh sistem saat melakukan proses data. Pengujian dilakukan pada halaman utama, halaman Virtual Tour, halaman $\log$ in, halaman utama admin, halaman edit panorama dan halaman panorama baru

\section{a) Pengujian Halaman Utama}

Pengujian dilakukan pada halaman utama. Berikut merupakan hasil pengujian yang dilakukan pada halaman utama.

\begin{tabular}{|l|lr|l|}
\hline \multicolumn{4}{|c|}{ TABEL 1 HASIL PENGUJAN PADA HALAMAN BERANDA } \\
$\begin{array}{c}\text { Uji } \\
\text { Skenario }\end{array}$ & \multicolumn{2}{|l|}{ Hasil Yang Diharapkan } & Keterangan \\
$\begin{array}{l}\text { Pilih tombol } \\
\text { start tour }\end{array}$ & $\begin{array}{l}\text { Menampilkan gambar } \\
\text { panorama }\end{array}$ & Berhasil \\
\hline $\begin{array}{l}\text { Pilih tombol } \\
\text { map }\end{array}$ & $\begin{array}{l}\text { Menampilkan peta } \\
\text { dengan tampilan map } \\
\text { default }\end{array}$ & Berhasil \\
\hline $\begin{array}{l}\text { Pilih tombol } \\
\text { satellite }\end{array}$ & $\begin{array}{l}\text { Menampilkan peta } \\
\text { dengan } \\
\text { satellite }\end{array}$ & tampilan & Berhasil \\
\hline $\begin{array}{l}\text { Pilih tombol } \\
\text { zoom in }\end{array}$ & $\begin{array}{l}\text { Memperbesar tampilan } \\
\text { peta }\end{array}$ & Berhasil \\
\hline $\begin{array}{l}\text { Pilih tombol } \\
\text { zoom out }\end{array}$ & $\begin{array}{l}\text { Memperkecil tampilan } \\
\text { peta }\end{array}$ & Berhasil \\
\hline
\end{tabular}

\begin{tabular}{|c|lr|l|}
\hline $\begin{array}{c}\text { Uji } \\
\text { Skenario }\end{array}$ & \multicolumn{2}{|l|}{ Hasil Yang Diharapkan } & Keterangan \\
\hline $\begin{array}{l}\text { Pilih tombol } \\
\text { full screen }\end{array}$ & $\begin{array}{l}\text { Menampilkan peta } \\
\text { dengan mode layar } \\
\text { penuh }\end{array}$ & Berhasil \\
\hline
\end{tabular}

\section{b) Pengujian Halaman Virtual Tour}

Pengujian dilakukan pada halaman utama. Berikut merupakan hasil pengujian yang dilakukan pada halaman virtual tour.

TABEL 2 HASIL PENGUJIAN PADA HALAMAN VIRTUAL TOUR

\begin{tabular}{|l|l|c|}
\hline Uji Skenario & Hasil Yang Diharapkan & Keterangan \\
\hline $\begin{array}{l}\text { Arahkan } \\
\text { Virtual Tour } \\
\text { dengan } \\
\text { mengusap } \\
\text { navigasi } \\
\text { arah }\end{array}$ & $\begin{array}{l}\text { Virtual Tour dapat } \\
\text { diarahkan ke atas, kanan, } \\
\text { bawah, dan kiri }\end{array}$ & Berhasil \\
\hline $\begin{array}{l}\text { Pilih tombol } \\
\text { gyro }\end{array}$ & $\begin{array}{l}\text { Virtual Tour dapat } \\
\text { diarahkan sesuai } \\
\text { orientasi dari perangkat } \\
\text { (hanya berfungsi pada } \\
\text { perankat yang memiliki } \\
\text { sensor gyro) }\end{array}$ & Berhasil \\
\hline $\begin{array}{l}\text { Pilih tombol } \\
\text { zoom in }\end{array}$ & $\begin{array}{l}\text { Memperbesar gambar } \\
\text { panorama }\end{array}$ & Berhasil \\
\hline $\begin{array}{l}\text { Pilih tombol } \\
\text { zoom out }\end{array}$ & $\begin{array}{l}\text { Memperkecil gambar } \\
\text { panorama }\end{array}$ & Berhasil \\
\hline $\begin{array}{l}\text { Pilih tombol } \\
\text { full screen }\end{array}$ & $\begin{array}{l}\text { Menampilkan Virtual } \\
\text { Tour dengan mode layar } \\
\text { penuh }\end{array}$ & Berhasil \\
\hline
\end{tabular}

c) Pengujian Halaman Log in

Pengujian dilakukan pada halaman $\log$ in. Berikut merupakan hasil pengujian yang dilakukan pada halaman $\log$ in.

TABEL 3 HASIL PENGUJIAN PADA HALAMAN LOGIN

\begin{tabular}{|l|l|l|}
\hline Uji Skenario & $\begin{array}{l}\text { Hasil Yang } \\
\text { Diharapkan }\end{array}$ & Keterangan \\
\hline $\begin{array}{l}\text { Pilih tombol } \\
\text { sign in dengan } \\
\text { memasukan } \\
\text { data dengan } \\
\text { benar }\end{array}$ & $\begin{array}{l}\text { Menampilkan } \\
\text { halaman } \\
\text { utama } \text { admin }\end{array}$ & Berhasil \\
\hline $\begin{array}{l}\text { Pilih tombol } \\
\text { sign in dengan } \\
\text { mengosongkan } \\
\text { data }\end{array}$ & $\begin{array}{l}\text { Menampilkan } \\
\text { utamanan admin }\end{array}$ & $\begin{array}{l}\text { Tidak Berhasil } \\
\text { (Menampilkan pesan } \\
\text { peringatan kesalahan: } \\
\text { "Harap isi bidang } \\
\text { ini“) }\end{array}$ \\
\hline
\end{tabular}




\begin{tabular}{|l|l|l|}
\hline Uji Skenario & $\begin{array}{l}\text { Hasil Yang } \\
\text { Diharapkan }\end{array}$ & Keterangan \\
\hline $\begin{array}{l}\text { Pilih tombol } \\
\text { sign in dengan } \\
\text { memasukkan } \\
\text { data yang } \\
\text { salah }\end{array}$ & $\begin{array}{l}\text { Menampilkan } \\
\text { halaman } \\
\text { utama admin }\end{array}$ & $\begin{array}{l}\text { Tidak Berhasil } \\
\text { (Menampilkan pesan } \\
\text { peringatan kesalahan: } \\
\text { "These credentials do } \\
\text { not match our } \\
\text { records“ }\end{array}$ \\
\hline
\end{tabular}

\section{d) Pengujian Halaman Utama Admin}

Pengujian dilakukan pada halaman utama admin. Berikut merupakan hasil pengujian yang dilakukan pada halaman utama admin.

TABEL 4 HASIL PENGUJIAN PADA HALAMAN UTAMA ADMIN

\begin{tabular}{|c|c|c|}
\hline Uji Skenario & Hasil Yang Diharapkan & Keterangan \\
\hline $\begin{array}{l}\text { Pilih tombol } \\
\text { create new } \\
\text { panorama }\end{array}$ & $\begin{array}{l}\text { Menampilkan halaman } \\
\text { panorama baru }\end{array}$ & Berhasil \\
\hline $\begin{array}{l}\text { Pilih tombol } \\
\text { map }\end{array}$ & $\begin{array}{ll}\text { Menampilkan } & \text { peta } \\
\text { dengan tampilan } & \text { map } \\
\text { default } & \end{array}$ & Berhasil \\
\hline $\begin{array}{l}\text { Pilih tombol } \\
\text { satellite }\end{array}$ & $\begin{array}{l}\text { Menampilkan peta } \\
\text { dengan tampilan satellite }\end{array}$ & Berhasil \\
\hline $\begin{array}{l}\text { Pilih tombol } \\
\text { zoom in }\end{array}$ & $\begin{array}{l}\text { Memperbesar tampilan } \\
\text { peta }\end{array}$ & Berhasil \\
\hline $\begin{array}{l}\text { Pilih tombol } \\
\text { zoom out }\end{array}$ & $\begin{array}{l}\text { Memperkecil tampilan } \\
\text { peta }\end{array}$ & Berhasil \\
\hline $\begin{array}{l}\text { Pilih tombol } \\
\text { full screen }\end{array}$ & $\begin{array}{l}\text { Menampilkan } \\
\text { dengan mode } \\
\text { penuh }\end{array}$ & Berhasil \\
\hline
\end{tabular}

\section{e) Pengujian Halaman Panorama Baru}

Pengujian dilakukan pada halaman panorama baru. Berikut merupakan hasil pengujian yang dilakukan pada halaman panorama baru.

TABEL 5 HASIL PENGUJIAN PADA HALAMAN PANORAMA BARU

\begin{tabular}{|c|c|c|}
\hline Uji Skenario & Hasil Yang Diharapkan & Keterangan \\
\hline $\begin{array}{l}\text { Pilih tombol } \\
\text { create dengan } \\
\text { memasukkan } \\
\text { data yang } \\
\text { benar }\end{array}$ & $\begin{array}{lll}\begin{array}{l}\text { Membuat } \\
\text { dengan }\end{array} & \text { titik } & \text { lokasi } \\
\text { panorama } & & \text { gambar } \\
\end{array}$ & Berhasil \\
\hline $\begin{array}{ll}\text { Pilih } & \text { tombol } \\
\text { map } & \end{array}$ & $\begin{array}{ll}\text { Menampilkan } & \text { peta } \\
\text { dengan tampilan } & \text { map } \\
\text { default } & \end{array}$ & Berhasil \\
\hline $\begin{array}{l}\text { Pilih tombol } \\
\text { satellite }\end{array}$ & $\begin{array}{l}\text { Menampilkan peta } \\
\text { dengan tampilan satellite }\end{array}$ & Berhasil \\
\hline $\begin{array}{l}\text { Pilih tombol } \\
\text { zoom in }\end{array}$ & $\begin{array}{l}\text { Memperbesar tampilan } \\
\text { peta }\end{array}$ & Berhasil \\
\hline
\end{tabular}

\begin{tabular}{|l|l|l|}
\hline Uji Skenario & Hasil Yang Diharapkan & Keterangan \\
\hline $\begin{array}{l}\text { Pilih tombol } \\
\text { zoom out }\end{array}$ & $\begin{array}{l}\text { Memperkecil tampilan } \\
\text { peta }\end{array}$ & Berhasil \\
\hline $\begin{array}{l}\text { Pilih tombol } \\
\text { full screen }\end{array}$ & $\begin{array}{l}\text { Menampilkan peta } \\
\text { dengan mode layar } \\
\text { penuh }\end{array}$ & Berhasil \\
\hline
\end{tabular}

\section{f) Pengujian Halaman Panorama Edit}

Pengujian dilakukan pada halaman panorama edit. Berikut merupakan hasil pengujian yang dilakukan pada halaman panorama edit.

TABEL 6 HASIL PENGUJIAN PADA HALAMAN PANORAMA EDIT

\begin{tabular}{|l|l|l|}
\hline Uji Skenario & Hasil Yang Diharapkan & Keterangan \\
\hline $\begin{array}{l}\text { Pilih tombol } \\
\text { create dengan } \\
\text { memasukkan } \\
\text { data yang } \\
\text { benar }\end{array}$ & $\begin{array}{l}\text { Membuat titik lokasi } \\
\text { dengan gambar } \\
\text { panorama }\end{array}$ & Berhasil \\
\hline $\begin{array}{l}\text { Pilih tombol } \\
\text { map }\end{array}$ & $\begin{array}{l}\text { Menampilkan peta } \\
\text { dengan tampilan map } \\
\text { default }\end{array}$ & Berhasil \\
\hline $\begin{array}{l}\text { Pilih tombol } \\
\text { satellite }\end{array}$ & $\begin{array}{l}\text { Menampilkan peta } \\
\text { dengan tampilan } \\
\text { satellite }\end{array}$ & Berhasil \\
\hline $\begin{array}{l}\text { Pilih tombol } \\
\text { zoom in }\end{array}$ & $\begin{array}{l}\text { Memperbesar tampilan } \\
\text { peta }\end{array}$ & Berhasil \\
\hline $\begin{array}{l}\text { Pilih tombol } \\
\text { zoom out }\end{array}$ & $\begin{array}{l}\text { Memperkecil tampilan } \\
\text { peta }\end{array}$ & Berhasil \\
\hline $\begin{array}{l}\text { Pilih tombol } \\
\text { full screen }\end{array}$ & $\begin{array}{l}\text { Menampilkan peta } \\
\text { dengan mode layar } \\
\text { penuh }\end{array}$ & Berhasil \\
\hline $\begin{array}{l}\text { Pilih tombol } \\
\text { edit }\end{array}$ & $\begin{array}{l}\text { Menampilkan dialog } \\
\text { box data gambar } \\
\text { panorama }\end{array}$ & Berhasil \\
\hline $\begin{array}{l}\text { Pilih tombol } \\
\text { connect }\end{array}$ & $\begin{array}{l}\text { Membuat koneksi antar } \\
\text { gambar panorama }\end{array}$ & Berhasil \\
\hline $\begin{array}{l}\text { Pilih tombol } \\
\text { delete }\end{array}$ & $\begin{array}{l}\text { Menghapus titik lokasi } \\
\text { dan gambar panorama }\end{array}$ & Berhasil \\
\hline
\end{tabular}

\section{2) Pengujian UAT (User Acceptance Test)}

\section{a) Perhitungan Kuesioner}

Beberapa aspek dalam pengujian yang dilakukan terhadap responden yaitu aspek kemudahan dan kegunaan. Kedua aspek tersebut menjadi poin utama penilaian yang akan diukur untuk mengetahui sejauh mana pengguna (responden) memberikan responnya atau feedback terhadap aplikasi Virtual Tour bandar udara internasional supadio yang dibangun. Setiap aspek diukur berdasarkan range 1 hingga 5 , yang dimaknai dari negatif ke positif. Sehingga angka 5 adalah angka maksimal dari setiap poin pada setiap aspek

Pengujian responden terhadap "Aplikas Virtual Tour Bandar Udara Internasional Supadio" untuk mengetahui apakah sistem telah memenuhi tujuan seperti yang diharapkan. 
TABEL 7 HASIL PENGUJIAN KUESIONER

\begin{tabular}{|c|c|c|c|c|c|c|c|}
\hline \multirow{2}{*}{ No } & \multirow{2}{*}{ Pernyataan } & \multicolumn{4}{|c|}{ Respon } & \multicolumn{2}{|c|}{ Total } \\
\hline & & STS & TS & $\mathrm{CS}$ & $\mathrm{S}$ & SS & \\
\hline 1 & $\begin{array}{l}\text { Apakah } \\
\text { pengguna } \\
\text { dapat } \\
\text { mengakses } \\
\text { aplikasi } \\
\text { Virtual } \\
\text { Tour } \\
\text { dengan } \\
\text { mudah? }\end{array}$ & 2 & 1 & 3 & 17 & 26 & 49 \\
\hline 2 & $\begin{array}{l}\text { Apakah } \\
\text { aplikasi } \\
\text { Virtual } \\
\text { Tour dapat } \\
\text { terinstall ke } \\
\text { perangkat } \\
\text { yang } \\
\text { digunakan? }\end{array}$ & 2 & 2 & 5 & 12 & 28 & 49 \\
\hline 3 & $\begin{array}{l}\text { Apakah } \\
\text { kualitas } \\
\text { gambar } \\
\text { panorama } \\
\text { sangat } \\
\text { baik? }\end{array}$ & 1 & 3 & 8 & 18 & 19 & 49 \\
\hline 4 & $\begin{array}{l}\text { Apakah } \\
\text { user } \\
\text { interface } \\
\text { (antarmuka } \\
\text { pengguna) } \\
\text { yang } \\
\text { digunakan } \\
\text { mudah } \\
\text { digunakan } \\
\text { dan jelas } \\
\text { bagi } \\
\text { pengguna? }\end{array}$ & 2 & 3 & 6 & 15 & 23 & 49 \\
\hline 5 & $\begin{array}{l}\text { Apakah } \\
\text { huruf yang } \\
\text { digunakan } \\
\text { mudah } \\
\text { dibaca dan } \\
\text { jelas bagi } \\
\text { pengguna? }\end{array}$ & 1 & 1 & 5 & 18 & 24 & 49 \\
\hline 6 & $\begin{array}{l}\text { Apakah } \\
\text { menu } \\
\text { navigasi } \\
\text { pada } \\
\text { aplikasi } \\
\text { Virtual } \\
\text { Tour dapat } \\
\text { berfungsi } \\
\text { dengan } \\
\text { baik? }\end{array}$ & 2 & 3 & 6 & 22 & 16 & 49 \\
\hline 7 & $\begin{array}{l}\text { Apakah } \\
\text { gambar } \\
\text { panorama } \\
\text { pada } \\
\text { aplikasi }\end{array}$ & 2 & 1 & 1 & 26 & 19 & 49 \\
\hline
\end{tabular}

\begin{tabular}{|c|c|c|c|c|c|c|c|}
\hline & $\begin{array}{l}\text { Virtual } \\
\text { Tour dapat } \\
\text { dilihat } \\
\text { dengan } \\
\text { baik? }\end{array}$ & & & & & & \\
\hline 8 & $\begin{array}{l}\text { Apakah } \\
\text { fasilitas } \\
\text { gyroscope } \\
\text { pada } \\
\text { aplikasi } \\
\text { berfungsi } \\
\text { dengan } \\
\text { baik? }\end{array}$ & 1 & 1 & 6 & 29 & 12 & 49 \\
\hline 9 & $\begin{array}{l}\text { Apakah } \\
\text { pengguna } \\
\text { merasa } \\
\text { terbantu } \\
\text { dengan } \\
\text { adanya } \\
\text { aplikasi } \\
\text { ini? }\end{array}$ & 2 & 1 & 4 & 8 & $4^{1}$ & 49 \\
\hline 10 & $\begin{array}{l}\text { Apakah } \\
\text { informasi } \\
\text { yang } \\
\text { disediakan } \\
\text { sudah } \\
\text { memenuhi } \\
\text { kebutuhan } \\
\text { saudara? }\end{array}$ & 2 & 1 & 3 & 24 & 19 & 49 \\
\hline \multicolumn{2}{|c|}{ Jumlah } & 17 & 17 & 47 & $\begin{array}{l}20 \\
9\end{array}$ & 200 & $\begin{array}{l}49 \\
0\end{array}$ \\
\hline \multicolumn{2}{|c|}{ Persentase } & 3,46 & $\begin{array}{l}3,4 \\
6\end{array}$ & 9,59 & $\begin{array}{l}42 \\
6 \\
5\end{array}$ & $\begin{array}{l}40,8 \\
1\end{array}$ & $\begin{array}{l}10 \\
0\end{array}$ \\
\hline
\end{tabular}

Pada Tabel 7 dapat diketahui informasi antara lain:

a) Jumlah responden pengguna bandar udara sebanyak 49 orang.

b) Pilihan "Sangat Setuju" yang dipilih responden pengguna bandar udara berjumlah 200 jawaban dan memiliki persentase $(200 / 490) \times 100 \%=$ 40,81\%.

c) Pilihan "Setuju" yang dipilih responden pengguna bandar udara berjumlah 209 jawaban dan memiliki persentase $(209 / 490) \times 100 \%=$ 42,65\%.

d) Pilihan "Cukup Setuju" yang dipilih responden pengguna bandar udara berjumlah 47 jawaban dan memiliki persentase (47/490) x 100\%= 9,59\%.

e) Pilihan "Tidak Setuju" yang dipilih responden pengguna bandar udara berjumlah 17 jawaban dan memiliki persentase (17/490) x 100\%= $3,46 \%$.

f) Pilihan "Sangat Tidak Setuju" yang dipilih responden pengguna bandar udara berjumlah 17 jawaban dan memiliki persentase (17/490) $\mathrm{x}$ $100 \%=3,46 \%$

b) Perhitungan Kuesioner Berdasarkan Koresponden 
Perhitungan yang dilakukan berdasarkan hasil pengujian kuesioner terhadap responden pengguna bandara internasional supadio.

Hasil pengujian berdasarkan responden masyarakat dapat dilihat pada Tabel 8

TABEL 8 RESPONDEN PENGGUNA BANDAR UDARA

\begin{tabular}{|c|c|c|c|c|c|c|c|c|c|c|c|}
\hline \multirow[t]{2}{*}{ Responden } & \multicolumn{10}{|c|}{ Pertanyaan } & \multirow{2}{*}{$\begin{array}{l}\text { Tot } \\
\text { al }\end{array}$} \\
\hline & 1 & 2 & 3 & 4 & 5 & 6 & 7 & 8 & 9 & 10 & \\
\hline 1 & 4 & 4 & 4 & 4 & 4 & 4 & 5 & 4 & 4 & 5 & 42 \\
\hline 2 & 1 & 1 & 1 & 1 & 1 & 1 & 1 & 1 & 1 & 1 & 10 \\
\hline 3 & 5 & 5 & 5 & 5 & 5 & 4 & 4 & 4 & 4 & 4 & 45 \\
\hline 4 & 5 & 5 & 4 & 4 & 4 & 3 & 4 & 3 & 4 & 4 & 40 \\
\hline 5 & 5 & 5 & 4 & 3 & 5 & 4 & 5 & 5 & 5 & 5 & 46 \\
\hline 6 & 4 & 4 & 4 & 5 & 5 & 4 & 4 & 4 & 4 & 4 & 42 \\
\hline 7 & 4 & 4 & 5 & 5 & 3 & 2 & 4 & 4 & 3 & 4 & 38 \\
\hline 8 & 4 & 5 & 5 & 5 & 5 & 5 & 4 & 4 & 4 & 4 & 45 \\
\hline 9 & 4 & 3 & 4 & 5 & 4 & 5 & 5 & 3 & 4 & 5 & 42 \\
\hline 10 & 5 & 5 & 5 & 4 & 4 & 4 & 5 & 4 & 3 & 4 & 43 \\
\hline 11 & 5 & 4 & 4 & 5 & 5 & 5 & 4 & 5 & 4 & 5 & 46 \\
\hline 12 & 5 & 4 & 3 & 4 & 4 & 3 & 4 & 4 & 3 & 4 & 38 \\
\hline 13 & 5 & 5 & 4 & 5 & 5 & 4 & 4 & 4 & 5 & 5 & 46 \\
\hline 14 & 4 & 5 & 5 & 5 & 5 & 4 & 4 & 3 & 4 & 4 & 43 \\
\hline 15 & 5 & 5 & 5 & 5 & 5 & 5 & 4 & 4 & 4 & 5 & 47 \\
\hline 16 & 5 & 5 & 5 & 5 & 5 & 5 & 5 & 5 & 5 & 5 & 50 \\
\hline 17 & 4 & 4 & 4 & 4 & 4 & 5 & 5 & 4 & 4 & 5 & 43 \\
\hline 18 & 1 & 1 & 2 & 1 & 2 & 2 & 2 & 3 & 1 & 1 & 16 \\
\hline 19 & 5 & 5 & 3 & 2 & 4 & 3 & 5 & 4 & 4 & 4 & 39 \\
\hline 20 & 5 & 5 & 3 & 4 & 4 & 4 & 4 & 4 & 4 & 4 & 41 \\
\hline 21 & 5 & 5 & 5 & 5 & 5 & 5 & 5 & 5 & 5 & 5 & 50 \\
\hline 22 & 5 & 5 & 5 & 5 & 5 & 5 & 5 & 5 & 5 & 5 & 50 \\
\hline 23 & 5 & 5 & 5 & 5 & 5 & 5 & 5 & 5 & 5 & 5 & 50 \\
\hline 24 & 5 & 4 & 4 & 4 & 4 & 4 & 4 & 3 & 4 & 3 & 39 \\
\hline 25 & 5 & 5 & 5 & 5 & 5 & 5 & 5 & 5 & 5 & 5 & 50 \\
\hline 26 & 4 & 3 & 3 & 4 & 4 & 4 & 4 & 4 & 4 & 4 & 38 \\
\hline 27 & 4 & 5 & 5 & 5 & 5 & 4 & 4 & 5 & 4 & 4 & 45 \\
\hline 28 & 2 & 2 & 2 & 2 & 3 & 4 & 4 & 4 & 4 & 3 & 30 \\
\hline 29 & 4 & 3 & 3 & 3 & 4 & 3 & 4 & 4 & 4 & 4 & 36 \\
\hline 30 & 5 & 5 & 5 & 5 & 5 & 5 & 5 & 5 & 5 & 5 & 50 \\
\hline 31 & 5 & 5 & 4 & 5 & 5 & 4 & 4 & 4 & 4 & 4 & 44 \\
\hline 32 & 5 & 5 & 5 & 5 & 5 & 5 & 5 & 4 & 5 & 4 & 48 \\
\hline
\end{tabular}


memberikan informasi kepada pengguna bandar udara internasional supadio.

4. Hasil dari pengujian blackbox, aplikasi berhasil beroperasi dengan baik dan bebas dari kesalahan.

5. Hasil dari pengujian UAT (User Acceptance Test), bedasarkan jawaban dari responden menghasilkan nilai persentase dengan rata rata $82,77 \%$ dan masuk dalam kriteria sangat layak untuk digunakan.

\section{DAFTAR PUSTAKA}

[1] Angkasa Pura II. (2020) Bandar Udara Internasional Supadio https://angkasapura2.co.id/id/business_relation/our_airport/21bandara-internasional-supadio. (Di akses pada 24 Aggustus 2020).

[2] Vidiardi, S. (2015) Pengembangan Museum Virtual Interaktif Menggunakan Teknologi Dekstop Virtual Reality pada Musem Ranggarwarsita. Semarang: Universitas Negeri Semarang.

[3] Tjin, E. (2013). Memotret Gambar Panorama Dengan Kamera DSLR.

[4] Osman, A., Wahab, N.A., \& Ismail, M.A. (2009) Development and Evaluation of an Interactive $360^{\circ}$ Virtual Tour for Tourist Destinations. Malaysia: Universiti Teknologi MARA.

[5] Sharma, N. (2016) New Age of Web-Apps. Progressive web application. https://www.slideshare.net/nehhasharma/progressiveweb-apps-66913345 (Diakses pada 24 Agustus 2020)

[6] Pramana, G.Y. (2010) Penerapan Metode Image Stitching pada pembuatan Virtual Reality pengenalan Islamic Centre Universitas Ahmad Dahlan. Yogyakarta: Universitas Ahmad Dahlan

[7] Laurensius, A. (2017) Platform e-Learning untuk Pembelajaran Pemrograman Web Menggunakan Konsep Progressive Web Apps. Surabaya: Institut Teknologi Sepuluh November

[8] Melky, F. (2015) Rancang Bangun Aplikasi Virtual Tour Museum Provinsi Kalimantan Barat untuk Edukasi Sejarah. Pontianak: Universitas Tanjungpura

[9] Horonjeff, R.D. (1975) Noise Exposure Forecast Areas for Los Angeles International Airport. Springfield, Va: US Clearinghouse.

[10] Panggabean, R.F. (2015) Rancang Bangun Peta Virtual 3D Kampus UNTAN dengan Fitur Panorama $360^{\circ} \times 180^{\circ}$. Jurnal Teknik Informatika Universitas Tanjungpura.

[11] Brown., Matthew., Hartley, R.I \& Nister, D. (2007) Minimal Solutions for Panoramic Stitching, Microsoft Research.

[12] Brown, M.A. (2005) Multi-Image Matching using Invariant Features, Vancouver : The University of British Columbia.

[13] Bahari, C. C. B., \& Sumaryana, Y. (2019) Penerapan Progressive Web Apps Pada Aplikasi Lowongan Pekerjaan Dosen Universitas Perjuangan. Informatics and Digital Expert. Yogyakarta: STMIK AKAKOM

[14] Rosa, S. (2016) Pemodelan Visual dengan UML. Yogyakarta: Graha Ilmu.

[15] Rosa, A.S., \& Shalahuddin, M. (2013) Rekayasa Perangkat Lunak Terstruktur dan Berorientasi Objek. Bandung: Informatika Bandung.

[16] Kristanto, A. (2008). Perancangan Sistem Informasi dan Aplikasinya. Gava Media.

[17] Binanto, I. (2010). Multimedia digital-dasar teori dan pengembangannya. Penerbit Andi.

[18] Sidi, M.M., dkk. (2015). Pengujian Aplikasi menggunakan Black Box Testing Boundary Value Analysis (Studi Kasus : Aplikasi Prediksi Kelulusan SNMPTN). Jurnal Ilmiah Teknologi Informasi Terapan. Volume I, No 3.

[19] Sugiyono, D. (2008). Metode penelitian bisnis. Bandung: Pusat Bahasa Depdiknas.

[20] Scott Highton 2010, Virtual Reality Photography: Creating Panoramic And Object Images. California: San Carlos Dio, Safriadi, N., \& Sukamto, A. S. (2018). Rancang Bangun Aplikasi Virtual Tour Lokasi Rekreasi dan Hiburan Keluarga di Pontianak: JUSTIN (Jurnal Sistem dan Teknologi Informasi) 